\title{
FORUM*
}

\section{The knowledge base for instructional design (Short paper)}

\section{EGBERT WARRIES}

Department of Education, University of Twente, Enschede, The Netherlands

\section{Introduction: the boundaries of our knowledge}

As a member of a team founding a new department for training R\&D professionals six years ago, my task was preparing a programme for prospective instructional designers. In doing so I found some of the literature on instruction was relatively unusable for our prospective graduates.

In my view, the literature is still deficient. It has gaps, when compared with the knowledge we should like to put at students' disposal when they solve problems in practice. Also, its theories often concentrate on problems of learning and thinking, disregarding other instructional phenomena and seldom considering instruction as "knowledge of the artificial". Designers who are over-influenced by those theories are bound to work within an unnecessarily narrow domain of knowledge about instruction.

\section{Instruction as the subject of inquiry}

It seems difficult to investigate or to design instruction without presuming that it takes place within an instructional system. Indeed, I can hardly imagine that speaking of instruction per se suffices for those who wish to extend the knowledge base for instructional designers. The purpose of an instructional system is to produce specific changes in the capabilities of human beings; that is, their potential performance of certain intellectual or motor activities. Achievement and attitudes of learners entering into instruction could be considered as the input of the

\footnotetext{
* This is a new and unrefereed section, intended for such purposes as: rapid publication of summaries of work in progress (normally in the issue following receipt); outlines of projects or research themes in particular institutions; short papers expressing a strongly-held view or highlighting gaps in the literature; and conventional letters to the editor. We reserve the right to reject submissions or to require changes before publication.
} 
system. Their changed capabilities are the output. Almost always the functions of the system can be considered as deliberately sought influence on the learner, which can be characterized by authoritarian verbs but also by the rather permissive verb "to ask". Instruction may ask learners to read the study material, or listen to recorded or live lectures, or pose questions, summarize, review or exercise intellectual or motor skills.

Because there are different ways to ask people to do a specific thing, designers may use different instructional activities for the same function. Systematic investigation of instructional systems presumes a theory. What kind of theory should that be?

That theory must describe the reality of instructional systems. Like any other theory, it should contain a comprehensive set of propositions about what its subject looks like and how it works. It must describe reality in such a way that hypotheses can be inferred and tested. Theories in the literature show some preoccupations. For example, because instruction is mostly given to groups, it is no wonder that many empirically based theses are to be found about the structure of the classroom as an instructional system and relationships between teacher behaviour and other variables. Other theories pay attention to phenomena in individualized systems, where students work with a learning package or use a computer as an instructor.

Two further points: consider the view, held by many designers, that instructional theory gives prescriptions for instruction. I wouldn't venture to object to this normative view. Instead, I try here to reflect on the descriptive, explanatory and predictive connotations of the word "theory". This is especially important if our purpose should be to nurture a theory of instruction which may serve as a long-lasting future knowledge base for instructional designers.

Also, note that the conception of instruction as a legitimate subject of inquiry neither treats a student by necessity as a black box, nor holds that cognitive processes are to be neglected and that only overt behaviour is relevant.

\section{What can be prescribed?}

The difference between description and prescription has been discussed by instructional designers for more than twenty years. That discussion has centred on only one element in the system: the learner. The result is a gap between knowledge about thinking, learning and memory, on the one hand, and knowledge about instruction, on the other. The gap could be filled by developing an integrated set of recipes connecting cognitive science and educational practice. But what kind of prescriptive knowledge can we expect to develop?

I recognize that instructional designers use cognitive psychological knowledge, and I know that instructional design theory has made great strides in applying that knowledge to teaching young children. However, most of our detailed instructions 
in training in business and industry are not based on a prescriptive theory originating from this psychological knowledge. Most textbooks, courses and training in practice are developed on the basis of behavioural science and past experience of the designer, the latter sometimes legitimated by a bow toward a seemingly scientific theory. This is not a disaster. Instruction had to start as a set of techniques or strategies. Systematic description and theorizing came later. After all, Socrates practised inquiry teaching without having to develop a counterpart of Collins' theory and generations of teachers gave examples and general statements long before Merrill described his primary presentation forms.

The question remains, what can be prescribed solely on the basis of knowledge about human thinking and memory? Relatively little, when we deal with older students or training in corporations. From the standpoint of an instructional designer, aware of the large gap between theory and practice, this is not amazing. Knowledge about learning can lead to predictions about dependent variables after manipulating the independent ones, but the independent variables are still within the psychological domain and it is always hard to tell how to manipulate these. You need instruction for that.

To put this another way, cognitive science tells us about cognitive functioning during learning and desired changes in knowledge representation. Unfortunately, that knowledge is rarely in a form which can be used by instructional designers or theorists to alter the phenomena and to produce output of the instructional system.

To me it seems that the solution lies in describing what is going on in instructional systems and providing instructional designers with this description. Must this be merely superficial and must we neglect the real reasons why things happen in education the way they do? I do not think so. There is much to be discovered within the instructional system, extending our knowledge about why instructional phenomena take the form they do. And coming back to what we can prescribe, I think that every sound theory, either describing a natural or an artificial system, lets us predict what will happen to elements in the system if we manipulate variables in it. A theoretically-or empirically-based instructional description can take many forms and consists of statements on and observations of quite different instructions. Thus, it may contain the behaviour of an expert (or novice) teacher or any phenomena in any other instructional system. Predictions or, for that matter, prescriptions, can be drawn from such a body of knowledge.

\section{One instructional science or none?}

It seems questionable to me, that there will ever be some integrated theory of instructional design, based solely on our knowledge of human learning and functioning as a useful tool to designers of all types of instruction or a yardstick for criticizing instructional material developed by others. Three arguments support this: 
(a) history provides little evidence that this can really be done; (b) it would be necessary to know exactly what is going on in the mind of each learner; and (c) other important elements influencing the phenomena in instruction would be neglected.

All this seems to leave open the possibility of considering instructional theory as a metatheory or an outline of a metatheory, prescribing the format of usable instructional models. On the other hand, this possibility does not exist if we stick to my assumption that an instructional theory has aspects in common with all other scientific theories, in that it describes, explains and predicts phenomena. In that case, we are dealing with a theory about structure and functioning of a system. However, instructional systems are growing and dynamic and in particular they can be divided into groups of different systems, systems in which the interactions between teacher and students are prominent, systems in which the textbook is the main part, and so many other systems, each dealing with its own specific subject. Reasoning like this leads us to the conclusion that there will not be one comprehensive prescriptive theory, but there can be many instructional theories, theories that describe, explain and make predictions possible. They do though have things in common, which leaves open the chance of one instructional science, on a higher level of abstraction, but not prescriptive.

\section{What is new?}

Many others have had similar ideas about the knowledge base for instructional designers. In fact, there are several instances of important movements and work done in this vein. Military task analysis, elaboration theory of instruction and component display theory, mastery learning, inquiry teaching, teacher behaviour research and, more recently, research syntheses, all show that we can describe and investigate instructional phenomena or present deductive statements about instructional systems. For those who search for it, there is much evidence that instructional problems can be solved by using an instructional theory that deals with structure and phenomena of instructional systems.

I started with a type of needs assessment and I should like to end in the same vein. Instructional designers need a knowledge base, just as do engineers. Engineering is more than the application of science. I do not claim that in the short term a real instructional theory can be developed. Neither do I pretend to give the outline or the parameters for an instructional theory. In effect I do not suggest more than working towards a real instructional theory. Leave psychology alone for the time being and collect what has been found about what instruction looks like and how it works. The resultant theory could become something quite new: something we could use. 